122 Zersetzbarkeit des Chlorwasserstoffs - Salpetersäure durch Kupfcr.

erfolgt rascher, wenn man gasförmige Chlorwasserstoffsäure über gliuhendes, fein vertheiltes Kupfer leitet. In beiden Fällen entsteht nur Kupferchlorür. (Annalen d. Ch. u. Pharm. CXXXVI, $109-110$. .)

$G$.

Tabelle der specifischen Gewichte der wässrigen Salpetersăure nach $J$. Kolb.

Spec. Gewicht

1,000
1,007
1,014
1,022
1,029
1,036
1,044
1,052
1,060
1,067
1,075
1,083
1,091
1,100
1,108
1,116
1,125
1,134
1,143
1,152
1,161
1,171
1,180
1,190
1,199
1,210
1,221
$1,2: 31$
1,242
1,252
1,261
1,275

100 Theile enthalten bei $0^{\circ} \mathrm{C}$.

$\mathrm{NO}^{5} \quad \mathrm{HO}, \mathrm{NO}^{5}$

0,0

0,9

1,9

2,9

3,9

4,7

5,7

6,9

7,9

8,7

0,8

10,8

11.8

13,0

14,0

15,1

16,2

17,3

18,5

19,6

20,7

22,0

23,1

24,4

25,5

26,9

28,4

29,7

31,0

32,3

33,5

35,2
0,0

1,1

2,2

3,4

4,5

5,5

6,7

8,0

9,2

10,2

11,4

12,6

13,8

15,2

16,4

17,6

18,9

20,2

21,6

22,9

24,2

25,7

27,0

28,0

29,8

31,4

33,1

34,6

36,2

37,7

39,1

41,1
100 Theile enthalten bei $15^{\circ} \mathrm{C}$.

$\mathrm{NO}^{5}$

0,1

1,3

2,2

3,4

4,4

5,4

6,5

7,7

8,7

9,8

10,9

12,0

13,1

14,4

15,4

16,6

17,8

19,0

20,2

21,3

22,5

23,8

25,0

26,3

27,5

28,9

30,4

31,7

33,1

34,5

35,6

37,3
$\mathrm{HO}, \mathrm{NO}^{5}$

0,2

1,5

2,6

4,0

5,1

6,3

7,6

9,0

10,2

11,4

12,7

14,0

15,3

16,8

18,0

19,4

20,8

22,2

23,6

24,9

26,3

27,8

29,2

30,7

32,1

33,8

35,5

37,0

38,6

40,2

41,5

43,5 
Explosive Mischung. - Besondere Art der Auflösung des Jods. 123

Spec. Gewicht

\begin{tabular}{|c|c|c|}
\hline & $\mathrm{NO}^{5}$ & $\mathrm{HO}, \mathrm{NO}^{5}$ \\
\hline 1,286 & 36,5 & 42,6 \\
\hline 1,298 & 38,0 & 41,4 \\
\hline 1,309 & 39,5 & 46,1 \\
\hline 1,321 & 41,14 & 48,0 \\
\hline 1,334 & 42,9 & 50,0 \\
\hline 1,346 & 44,5 & 51,9 \\
\hline 1,359 & 46,3 & 54,0 \\
\hline 1,372 & 48,2 & 56,2 \\
\hline 1,384 & 50,0 & 58,4 \\
\hline 1,398 & 52,1 & 60,8 \\
\hline 1,412 & 54,2 & 63,2 \\
\hline 1,426 & 56,7 & 66,2 \\
\hline 1,410 & 59,1 & 69,0 \\
\hline 1,454 & 61,9 & 72,2 \\
\hline 1,470 & 65,2 & 76,1 \\
\hline 1,485 & 68,7 & 80,2 \\
\hline 1,501 & 72,4 & 84,5 \\
\hline 1,516 & 75,8 & 88,4 \\
\hline 1,524 & 77,6 & 90,5 \\
\hline 1,530 & 79,0 & 92,2 \\
\hline 1,532 & 79,5 & 92,7 \\
\hline 1,541 & 81,4 & 95,0 \\
\hline 1,549 & 83,4 & 97,3 \\
\hline 1,559 & 85,71 & 100,0 \\
\hline
\end{tabular}

(Amnal. d. chim. et d. phys. 4 me Sér. Févr. 1867. tom. X pag. $136-144)$.
100 Theile enthalten

$\begin{array}{cc}\mathrm{NO}^{5} & \mathrm{HO} \mathrm{NO}^{5} \\ 38,6 & 45,0 \\ 40,4 & 47,1 \\ 41,7 & 48,6 \\ 43,5 & 50,7 \\ 45,3 & 52,9 \\ 47,1 & 55,0 \\ 49,1 & 57,3 \\ 51,1 & 59,6 \\ 52,9 & 61,7 \\ 53,3 & 64,5 \\ 57,9 & 67,5 \\ 60,5 & 70,6 \\ 63,8 & 74,4 \\ 67,2 & 78,4 \\ 71,1 & 83,0 \\ 74,7 & 87,1 \\ 79,4 & 92,6 \\ 82,3 & 96,0 \\ 84,0 & 98,0 \\ 85,71 & 100,0\end{array}$

H. Ludwig. bei $15^{\circ} \mathrm{C}$.

\section{Die explosive Mischung}

von John Horsley besteht aus 9 Th. gutgetrocknetem, feingepulvertem chlorsaneren $\mathrm{Kali}$ und $3 \mathrm{Th}$. Galläpfelpulver, die durch feine Metallsiebo gemischt werden. - Auch die Kraft des gewöhnlichen Schiesspulvers wird durch einen Zusatz von 12\% Galläpfelpnlver vermehrt. (Polytechn. Notizblatt).

Dr. Reich.

\section{Eine besondere Art der Auflösung des Jods bei Gegenwart gewisser Silissstoffe}

beobachtete H. H lasiwetz. Wässrige Lösungen von $\mathrm{Orc}$ in, Resorçin und Phloroglycin zeigen die auffallende Eigenschaft, dass sie, besonder's beim Erwärmen, beträchtliche Men- 